\title{
LACK OF MOTIVATION FACTORS CREATING POOR ACADEMIC PERFORMANCE IN THE CONTEXT OF GRADUATE ENGLISH DEPARTMENT STUDENTS
}

\author{
ISLAHUL MAULIYA \\ Universitas Ahmad Dahlan \\ liyaislahul@gmail.com \\ RESTY ZULEMA RELIANISA \\ Universitas Ahmad Dahlan \\ restyzulema26@gmail.com \\ UMY ROKHYATI \\ Universitas Ahmad Dahlan \\ umy.rokhyati@pbi.uad.ac.id
}

DOI : http://dx.doi.org/10.29300/ling.v6i2.3604

Received: September 16th 2020 Accepted: November 25th $2020 \quad$ Published: December 3rd 2020

\begin{abstract}
At the graduate level, students' poor performance cuts across almost all the compulsory subjects in which English is inclusive. Poor academic performance of students is one problem impeding the smooth actualization of the educational purpose, which is to prepare an individual for mentally serving both himself and society. Therefore, the primary purpose of this research is to discover the internal factors, such as lack of motivation factors contributing to the poor academic performance of graduate students of the English Department. In this research, researchers selected three participants and utilized an interview as the method to collect the data, and interview guidelines as the instrument. The authors analysed the data qualitatively and explained the findings descriptively. Several things will affect students' academic performance, especially those related to motivation. It starts from within the students themselves, from the family environment, and even lecturers greatly affect student motivation in improving academic performance. It should not only focus on the mistakes made by students, as there must be a cause behind it all. In a nutshell, the results of this study revealed that one aspect of internal factors causing poor academic performance was the lack of motivation derived from two sizeable directions, family and teacher.
\end{abstract}

Keywords: Poor academic performance, education, learning, graduate students, lack of motivation

\section{INTRODUCTION}

Education is a necessity for every social creature who feels inadequate because it isanattempttoimprovethequalityofthemselves, knowledge, and hidden potential. In present times,education is inseparable from human life. Knight (2006) asserts that education is a life long learning process that can occur in a variety of endless life contexts. Hence, it can be

How to cite this article:Mauliya, I., Relianisa, R. Z., \& Rokhyati, U. (2020). Lack of motivation factors creating poor academics performance in the context of graduate English department students. Linguists : Journal Of Linguistics and Language Teaching, 6(2), 73-85. doi: http://dx.doi.org/10.29300/ling.v6i2.3604 
broadly interpreted that education refers to the process of learning something in life and all forms of individual interaction with the environment, either formally or informally. Meanwhile, in simple terms, education is explained as the learning process of an individual in a formal form called teaching.

Humans possess a natural ability to learn, in which the process will occur throughout their lives until they die. In general, several aspects of the learning process encompass experiences, perspectives or different views, ways of thinking, debating, and changing mindsets. Therefore, if one experiences a change in behavior, then it is the result of an experience that can be interpreted as learning. These behaviors appear in the form of physical floating, openness or intellect, and behavior not easily seen.

Students in current learning are faced with challenging situations, such as inside and outside classroom learning, initiating several problems, for instance, lack of focus and concentration. Drozdenko, Tesch, and Coelho (2012) mention that two significant factors interfering learning in the classroom are external and internal disturbance originated from the students' disintegration. Some examples of external disturbance are hard to understand instructions, class temperature, and students prefer listening to music rather than paying attention to their teachers. Meanwhile, internal disturbance covers those coming from students themselves, such as lack of motivation, laziness, prefer playing with other classmates, and the desire to eat in class. In addition, when discussing graduate students, there are some examples of external disturbance are extracurricular academic factors, work and financial situation, family problems and social and emotions problems (AL-Muslawi \& Hamid, 2020). Next is the internal disturbance, this things arises from students' competence and aptitude, class: size, schedule, environment, text books and exams, learning facilities and technology (AL- Muslawi \& Hamid, 2020).

Social-economic, psychological, and environmental factors have a significant impact on student performance. According to Hansen (2000), student performance is influenced by various factors, such as learning abilities affected by a new learning paradigm, which assumes that all students can and must learn at a higher level. However, it is not the only obstacle, considering some other factors becoming obstacles, such as race and gender, which affect students' performance (Ghazvini \& Khajehpour, 2011). Kitta and Sumra (2008) state that healthy interpersonal relationships between personnel in the campus environment will help to create a conducive environment for learning. This healthy relationship will attract and maintain students' academic interest starting from the quality of learning, leading to good achievement in learning. 
In regard to the internal factors affecting poor academic performance, emotion is something truly embedded in every individual. According to Karande and Kulkarni (2005), unstable emotions lead to a decrease in students' academic performance. Mood swing from initially calm to angry can sometimes occur in the classroom due to unpleasant feelings during the learning process. In addition, material mastery is also one of the internal factors causing students having poor academic performance. In previous research revealed that exams were difficult for students as they have a lot of material to learn and should absorb the material simultaneously (Azmi et al.,2014).

Another internal factor causing students' poor performance is a lack of motivation from within themselves. Carnegie Mellon University (2019), argue that the reasons why students are less motivated when learning are that they do not believe their efforts will improve their performance and that they have other priorities more preoccupying their attention. Dişlen (2013) also argued, students are less motivated and have poor academic performance due to boring lessons and complex tasks without a detailed explanation from the lecturer. Wright (2011) also states that feeling of being unable to do the given tasks, less confident in learning and having deficient relationship or communication with lecturers also cause students to have low motivation.

The current situation at the university which is used as a research setting shows that there are several factors that make students have poor academic performance. They show that external factors come from family, economic problems and condition in the classroom. While internal factor come from laziness.

In short, it can be concluded that various factors largely influence students' poor performance. These factors originate from within the students themselves and outside the environment. However, in this study, the researchers wanted to discover whether internal factors, such as lack of motivation, influence students' poor performance. The authors selected the English Postgraduate Program students for this research because the researchers were also students and lecturers in the same department. Moreover, the researchers also wanted to dedicate this research to make the Postgraduate Program in the English Department a better program in the future. Therefore, it was easier for researchers to obtain the required data.

\section{Motivation}

Motivation is one of the crucial internal factors influencing students' academic performance among various factors. According to Hading (2006), motivation refers to a mental stimulus driving and directing human behavior, involving learning behavior. Bialik, Bogan, Fadel, and Horvathova (2015) in Afriani explain that there are six important character qualities that someone should have, one of the is motivation. Likewise, Baharuddin (2008) 
motivation is one of the psychological factors that can affect student achievement. It is for the reason that, in motivation, there are dynamic elements in learning, such as emotions, attention, willingness, and others. Motivation not only grows from within the students themselves, but it can also arise from other people or the environment. After all, it can generate stimuli that delight students; thereby, they are always eager and have enthusiasm for learning (Djaali, 2014).

\section{Lack of Motivation}

Sasson (2019) explains that a lack of motivation refers to having a deficient level of passion and enthusiasm in doing a job. Furthermore, Shore (2017) also mentions that a lack of motivation can be interpreted as an uncaring attitude toward what one supposed to do. Japari School (2018), low motivation has been experienced by everyone, including students, as it is a situation where a student does not want to learn due to the difficulty in following the lesson. As students do not understand what they are learning in class, they end up feeling unmotivated (Barse, 2015). Greate School (2014) also states that a deficient level of students' confidence, the unrealized expectations in the classroom, unappreciated or unsupported by the family, and the high-pressure cause students to have low motivation in learning, resulting in poor academic performance. Huitt (2005), the reasons students become unmotivated are due to the teacher being unclear in delivering the lesson, having low self-confidence, dissatisfaction while learning, and personal problems from students.

\section{Academic Performance}

Before going further to the discussion about the lack of motivation factors contributing to the poor academic performance of students, the researchers will firstly explain what academic performance or what poor academic performance is. According to Ballotpedia (2019), academic performance can be defined a measure of achievement in which students succeed in obtaining results from various academic subjects. According to Williams (2018), when talking about academic performance is often associated with students' GPA; however, academic performance can also be regarded as an accomplishment of scientific achievements and skills, impressive test scores, extracurricular achievements, students' ability to lead if assigned to. Academic performance, according to Ghanney and Aniagyei (2014), is something able to be achieved by students when they are tested with what has been taught, the academic performance here focuses more on intellectual capacity.

If academic performance is a measure of student achievement, then poor academic performance is an achievement that does not meet standards. Poor academic performance is any performance that cannot meet targets, adequate standards, and expectations, or desires (David, 2013). Poor academic performance refers to the termination of effort caused by fear of doing something (Al-Zoubi and Younes 2015). A student still strives to reach the goal but 
cannot succeed in achieving it. Similarly, according to Siqueira and GurGe-Giannetti (2011), poor academic performance can also be interpreted as a result of school achievement below expectations and a lack of cognitive skills. Aremu and Sokan (2003) assert that poor academic performance can be explained as measured performance, but the results are below the expected standard. Moreover, Asikhia (2010) also reveals that poor academic performance is accomplishment below the standards that should be achieved.

The explanation above uncovers that academic performance refers to something measured and has results. In contrast, poor academic performance is the result of what is measured, but it does not meet the expectations or standards of achievement. In terms of causes, according to Ghanney and Aniagyei (2014), the contributing factors why students have poor academic performance are the lack of school facilities, difficulty managing the students, parents' ignorance of their children's needs, and the teachers' limitations in teaching. Social status is also believed to be one of the causes of students having poor academic performance (David, 2014). In addition, Nghambi (2014) \& Afriani, et.al. (2020) also adds that non-conducive teachers' working environment, inadequate supply of teaching materials and learning processes, teachers' lack of motivation, insufficient teacher training, inappropriate governmentpolicies, lack of learning methods, and lack of care from parents for their children are several factors causing a student to have poor academic performance.

The problem arises critically since every student can possess poor academic performance. Various reasons cause poor academic performance, such as the geographical area of their residence, cultural background, student history, educational approach, and general knowledge of students. Karande and Kulkarni (2005) have classified factors affecting student academic performance into three parts; psychological, biological (student-born factors), and social. They admit that the lack of biological conditions will result in belowaverage IQ. Psychologically, the teacher and the environment around students should understand that they are ready to learn or have the motivation to learn. From the social point of view, it focuses on whether their environment is conducive or not for the realization of an ideal learning environment, or whether they have the required material that can help them to improve learning motivation. According to Karande and Kulkarni (2005), the probable solutions to overcome this problem are to be multi-varied, cross-linked, and integral. Thus, the focus must change from class to family, environment, and social life of students.

Previous research conducted by Stover et al. (2012) concluded that there is a relationship between motivation and academic performance and psychological adjustment. A study conducted by the National Association of School Psychologists (2014) discovered that individuals with positive academic motivation demonstrate the characteristics of having a desire to learn, like related learning activities, and believe that schools are essential. Positive Linguists: Journal of Linguistics and Language Teaching Vol. 6, No. 2, December 2020 
academic motivation helps individuals to see that learning is useful and crucial in all aspects of academic life, work, and society.

\section{METHOD}

The writers employed a descriptive qualitative method because the data are presented qualitatively and can be analyzed descriptively. Some explanations support the reason why the writers utilized such a method. This study is descriptive as it aims to present, describe, and discover the internal factors affecting poor academic performance. According to Syakur (1993), the purpose of a descriptive study is to explain the facts, an identity of the thing being studied, and a situation that has been designed, concrete, precise, and explicit. Sometimes, it is ethically impossible to apply a scientific method to determine causal relationships between variables. In such a case, the descriptive method can produce precise information about something without impinging on the rights of research subjects. The research design utilized in this study was qualitative research. The writers analyzed and described the findings by providing data that can be analyzed and explained descriptively.

\section{Respondents}

Three participants were selected for this study to enrich the data or information obtained. There is no regulation on how many participants are considered sufficient to retrieve data in qualitative research. It depends on the purpose of the study because the participants are not randomly chosen. As stated by Cohen, Manion, and Morrison (2011), there is no clear rule in determining the number of samples in qualitative research since it relies on the fitness toward the purpose. There are several criteria why researchers choose the respondents. First, they are students who have jobs. Second, they are married and they do not really like how some lecturers teach them.

\section{Instruments}

The researchers utilized an in-depth interview as the method to collect the data and interview guidelines as the instrument. An interview is one of the methods used in qualitative research. An in-depth interview was used in this research because it assisted the researchers in obtaining more dense and deep data. Through this in-depth interview, existing questions could be easier to develop according to the research needs and the answers of the correspondents. Moreover, the correspondents could be more precise and flexible in explaining each statement they made, and thereby there would be no misinterpretation of the obtained data. Cohen, Manion, and Morrison (2011) state that an interview refers to a flexible tool to collect data, and the response is also adjustable. It can be verbal, nonverbal (body language), spoken, and heard. 


\section{Procedures}

This research used interview to collect the data. Before doing the interview, the researchers made interview guideline that provides some questions related to each research question. The researchers interviewed the participants directly. Thus, the researchers contacted the participants through message to make an appointment and it was also to make sure whether they were able to be the participant or not. The researchers let the participants choose the place for the interview in order to make them comfortable in doing the interview. After making the appointment with all participants, the researchers met the participant one by one to do the interview. At the time of the interview, both of the participants were more flexible in determining the place for the interview. Both participants were more likely to ask the researchers where the interview could be conducted. In conducting the interview, the researchers asked all questions in friendly way so that the participants did not feel under pressure. The researchers used Indonesian language so that the participants were not confused in answering every question. Using Indonesian language also allowed the researchers in understanding the information obtained and also facilitated the researchers in processing the data. The researchers also recorded the interview using the audio recorder to keep the data. The time allocation for the interview was around 20 minute or even more.

\section{Data analysis}

After the data was collected, the next step was analyzing the data. The first step done was changing the audio results from interview to word dataor it was called as transcript data analysis. Thus, the researchers wrote down all the participants' words and it was also used to check whether all the questions had been asked and answered or not. The researchers put all things that the participants mentioned into the transcripts data. The researchers gave the initial name when the researchers put the data into coding. After the transcribing of the data completed, the researcher did member checking. According to Cohen, Manion, and Morrison (2011), member checking is a process of giving one or more questions to confirm the response of participants in answering the questions given. In the process of member checking the researcher also confirmed about the interpretation of the researchers whether in accordance with the response of participants. When the data had been transcribed, the researchers did the next phase. The researcher did the coding to analyze the data. Code is used to give a name or label that the researcher gives to a piece of text that contains an idea or information. According to Gibbs (2007), code is given to give the label for the text that says the same thing or is about the same thing that enables the researcher to identify similar information. There are some sequences in coding. The steps are open coding, analytical coding, axial coding, and the last is selective coding. 
FINDINGS AND DISCUSSION

Mauliya, Relianisa and Rokhyati

The Causative Factors On Lack Of Motivation Contributing To The Poor Academic Performance Faced By Graduate Students

The findings of this research were based on collected data from three participants interviewed. Based on the interview results, all participants asserted that one of the causes of poor academic performance was lack of motivation. The first participant said that "coercion from the family environment and lack of motivation in myself caused my poor academic performance". The second participant also expressed a similar opinion "one of the causes of my poor academic performance was the lack of motivation from within myself'. The third participant also conveyed the low motivation within themselves by saying, "one reason causing this is a factor from within ourselves". For example, we should have motivation originating from within ourselves. Without it, we would face difficulties in carrying out existing tasks". When a lack of motivation is believed as an internal factor causing poor academic performance, it means that motivation greatly influences how individuals pay attention to information specifically and understand learning material through their senses, thoughts, and experiences (Borderless Charity, 2017).

The participants also argued that a lack of motivation would significantly affect academic performance, especially if some students have several priorities. As one participant put it, "I think it is natural that when we are learning, lack of motivation arises as a considerable influence because it is not only from laziness but also from time and priority. Especially for those who are married, of course, their motivation will be different as their time and priority are not only for college but also for work and family". Regarding what the participants revealed, Green and Kelso (2006) argue that the motivation of older students will be different from others, seen from the experiences they have and the presence of more priorities. Students must be assisted by interactive classrooms and effective management practices to avoid a decrease in their motivation. It is for the reason that a lack of motivation will cause unsuccessful work in all fields.

As stated by the second participant, "If I do not have the motivation to do whatever it is, then everything will not succeed. It also applies to languagelearning". In line with the participant's statement, Lieb (1991) mentions that if a student does not have information making them motivated or a condition that can make them motivated, then all activities carried out will be in vain, primarily if the situation does not support them, such as anxiety excess and a high enough difficulty level of a lesson. Furthermore, not having motivation will influence someone to develop. As the third participant said, "because poor or low motivation can affect the willingness to progress and develop in an academic field, for example, when I am lazy and not highly motivated, I tend to postpone doing my obligations as a college 
student”. From this statement, Cerdan (2017) argues that motivation for a student is essential as it is what will make them develop, actively seeking information and resources and also guaranteeing success.

\section{Family Factors}

One reason for the lack of motivation conveyed by the participant was from the home environment. As the first participant said that "a parent ignoring his child will reduce our motivation as students to either go to college or do assignments". According to Greate School (2014), the home environment has an essential role in shaping a student's view and attitude toward learning. A house having a bad influence on children will be fatal as it causes them to have deficient competence and learning ability. As conveyed by Whitaker (2012), students having no support from their family or home, they will not be able to perform well in the school, resulting in low motivation, lack of moral values and norms, and lack of selfcontrol. Putting pressure on children is inappropriate, as the second participant said, "for me it may be due to the high pressure my parents put on me, causing a loss of concentration in class". According to Wong (2017), giving too much pressure from families especially parents relating to academics is inappropriate for student development, it will not make them motivated, and emphasis will not change what is believed by children because learning is not only about getting good grades but also enjoy the process. Additionally, when families demand children to succeed but not contributing to anything, even not giving motivation, it results in children being reluctant to learn. The third participant revealed that "when parents always sue their children without giving high motivation, it decreases my willingness to learn and results in me being less enthusiastic". According to Häfner (2017), positive or negative academic scores received by students are verydependent on how their parents are involved and provide motivation optimally.

\section{Teachers' Factor}

Teachers' role has also impacted on student motivation. All three participants shared this opinion. Likewise, Barse (2015) mentions that close relations and excellent communication between teachers and students increased students' motivation. Otherwise, it would decrease their motivation and deteriorate academic performance. Correspondingly, the incapability of the teacher in time management during the class also caused low motivation to learn (Carnegie Mellon University, 2019). One participant said that "the lack of motivation to learn to cause a decrease in academic performance is caused by lecturers not contributing appropriately, thereby teaching and learning activities will not be able to run. Moreover, the lack of motivation does not only come from words but can also come from the way lecturers 
teach". According to Rosanti (2017), teachers who can motivate students are those who are most likely to carry out successful learning activities in the classroom.

However, those who cannot build positive energy and are unable to encourage student creativity or trigger students to follow the learning process are considered as the teacher factor affecting students' low motivation and poor academic performance. Thesecond participant said that "what made me unmotivated was a factor of unprofessional lecturers who could not be role models for me due to their inability to handle the class and deliver the material". Teachers whose behavior cannot be used as role models, who have a bad learning approach, and who give heavy assignments will make students reluctant to enter the class and unmotivated to continue the learning process in class (Takase, Niitani, Imai, \& Okada, 2019). According to the third participant, "because there were lecturers who only focused on teaching while the methods used were inappropriate and old-fashioned, I then became lazy and was unable to take lessons in class. Moreover, what was expected by lecturers was sometimes incompatible with what they did in class". Learning approaches or learning methods are a link between the teacher and students during the learning process, the method of the learning process is a variable having a significant influence to motivate and support the academic value of students, hence, if it is unsuccessful, motivation and academic values of students will not be guaranteed (Sari, 2016).

\section{Ways to Avoid Lack of Motivation}

The three participants also mentioned several issues related to how they reduced the intensity of the lack of motivation. The first participant said that "the way to avoid lack of motivation is to keep motivating myself to continue studying. I usually encourage myself to learn by reading books every day, regardless of whether there are lectures or not. Then I also like watching videos to increase motivation about something I am learning”. Accordingly, Martin (2017) suggests to start creating a threat-free environment for yourself, do more fun and preferred activities to be more motivated in learning and to remember initial goals. The second participant also added, "it must be dealt with, and I deal with it by starting to like the field I am studying to reduce the lack of motivation". Similar to the statements above, the way they can do is to stay motivated and focused on the field they are on, such as by watching videos, listening to songs, looking for suitable resources for learning, reading books, playing with friends who have hobbies of learning the same thing, and do not forget to keep concentrating (Oxford Royale Academy, 2018).

The final way, according to the third participant, is "My way to avoid lack of motivation is to manage my time as best as possible because I feel I am not yet optimal in managing time”. Correspondingly, Heibutzki (2019) mentions that motivation and academic 
performance will decrease if students do not have excellent time management; it is intended that students can divide their time on more essential things first so as not to get stuck if they face many things. Summarizing from all the explanations above, several things will affect students' academic performance, especially those related to motivation. It starts from within the students themselves, from the family environment, and even lecturers greatly affect student motivation in improving academic performance. It should not only focus on the mistakes made by students, as there must be a cause behind it all.

\section{CONCLUSION}

From the results of this study, the researchers concluded that in internal factors, one thing causing poor academic performance was the lack of motivation of graduate students. Lack of motivation was ignited from two sizeable directions, family and teacher. Not having support from families caused a low level of motivation. Priority between family and college was also another reason for having low motivation. In addition, the continuous pressure put by the family, especially from parents, also greatly affected the academic performance of students. Moreover, factors of teachers, such as the way they teach, boring and old-fashioned teaching methods, the time they spend on teaching, and the lack of a good relationship between teachers and students will cause low motivation, and this leads to poor academic performance.

Based on the result of this research, the researchers provide recommendation for other researcher. The benefit that other researchers can be obtained from this research is they can know one of factors poor academic performance appear in university students. Other researchers may also be encouraged to conduct further related studies and use the results of this study as their reference. As for the example, the other researchers can investigate other internal or external factors in more detail. The other researcher who conducts the same research can involve more than three participants in one university or some students in some university. Thus, the finding of this study can be various and more complete.

\section{REFERENCES}

Afriani, Z.L. (2019). Character education reinforcement in EFL classroom. Edulingua: Jurnal Linguistiks Terapan dan Pendidikan Bahasa Inggris, 6(2), 69-76.

Afriani, Z.L. (2020). The effect of Question Answer Relationship (QAR) Strategy in enhancing students' reading comprehension. Journal of English Education and Teaching, 4(4), 548-558.

AL-Muslawi, I. A., \& Hamid, A. A. (2020). External and internal factors affacting students's academic performance. Sosial Sciences , I (1), 1-26.

Al-Zoubi, S. M., \& Younes, M. A. (2015). Low academic achievement: Causes and results. Theory and Practice in Language Studies, 2262-2268. 
Asikhia. (2010). Students and teachers' perception of the causes of poor academic performance in Ogun State secondary schools [Nigeria]: Implications for counseling for national development. European Journal of Social Sciences, 229-242.

Barse, M. (2015, August 16). Schools to blame for unmotivated students. Accessed from https://sciencenordic.com/children-and-adolescents-denmark-learning/schools-to-blame-forunmotivated-students/1421116.

Barse, M. (2015, August 16). Schools to blame for unmotivated students. Accessed from https://sciencenordic.com/children-and-adolescents-denmark-learning/schools-to-blame-forunmotivated-students/1421116.

Carnegie Mellon University. (2019, November 30). Students lack interest or motivation. Accessed from https://www.cmu.edu/teaching/solveproblem/strat-lackmotivation/index.html.

Carnegie Mellon University. (2019, November 30). Students lack interest or motivation. Accessed from https://www.cmu.edu/teaching/solveproblem/strat-lackmotivation/index.html.

Cerdan, A. G. (2017, October 30). The importance of motivation: What is it and tips to promote it.Accessed from https://blog.cognifit.com/importance-of-motivation-learning-tips/.

Charity, B. (2017, October 26). How motivation affects academic performance. Accessed from https://medium.com/@TheCharity/how-motivation-affects-academic-performancefcde79e8ef09

Cohen, L., Manion, L., \& Morrison, K. (2011). Research method ineducation. Routledge.

Cohen, L., Manion, L., \& Morrison, K. (2011). Research method ineducation. Routledge.

David, N. M. (2014). Determinants of poor academic performance of secondary school students in Sumbawanga District, Tanzania (Master thesis, Sokoine University of Agriculture, Morogoro, Tanzania). Accessed from http://hdl.handle.net/123456789/622.

Dişlen, G. (2013). The reasons of lack of motivation from the students' andteachers' voices. ASOSJOURNALAkademik Sosyal Araştırmalar Dergisi TheJournal of Academic Social Science, $36-45$.

Ghanney, R. A., \& Aniagyei, D. F. (2014). An investigation into the poor academic performance of students. Research on Humanities and Social Sciences, 4(9), 8-18.

Ghanney, R. A., \& Aniagyei, D. F. (2014). An investigation into the poor academic performance of students. Research on Humanities and Social Sciences, 4(9), 8-18.

Ghazvini, S. D., \& Khajehpour, M. (2011). Gender differences in factors affecting academic performance of high school students. Procedia- Social and Behavioral Sciences , 15 (1), 10401045.

Great School. (2014, September 10). Motivating the unmotivated student. Accessed from https://www.greatschools.org/gk/articles/motivating-the-unmotivated-student/.

Great School. (2014, September 10). Motivating the unmotivated student. Accessed from https://www.greatschools.org/gk/articles/motivating-the-unmotivated-student/.

Green, T. M., \& Kelso, C. M. (2006). Factors that affect motivation among adult learners. Journal of College Teaching \& Learning, 3(4), 65-74.

Häfner, I. (2017). The role of family characteristics for students' academicoutcomes: A personcentered approach. Child Development.

Hansen, L. (2006). Strategies for ELL Success. Scholarly Journal, 43(4), 22-25. Hansen, L. (2006). Strategies for ELL Success. Scholarly Journal, 43(4), 22-25. 
Huitt, W. (2005). Reasons for lack of motivation. Educational Psychology Interactive, 1.

Karande, S., \& Kulkarni, M. (2005). Poor school performance. Indian Journal ofPediatrics, 72, 961967.

Karande, S., \& Kulkarni, M. (2005). Poor school performance. Indian Journal ofPediatrics, 72, 961967.

Kitta, S., Sima, R. \& Sumra, R. (2008). Primary school leaving examinations: School-level efforts to improve performance. Dar es Salaam: TenMet

Lieb, S. (1991). Principles of adult learning. Vision, 1-3.

Nassaji, H. (2015). Qualitative and descriptive research: Data type versus data analysis. Language Teaching Research, 129-132.

Nghambi, G. H. (2014). Factors contributing to poor academic performance in certificate of secondary education examination for community secondary schools in Urambo District, Tabora, Tanzania (Master thesis, University of Tanzania, Tanzania). Planning and Policy Studies of The Open University of Tanzania, 1-94.

Psychologists, N. A. (2014). School psychologists help schools successfully. National Association of School Psychologists, 1-2.

Relianisa, R. Z., Mauliya, I., \& Rokhyati, U. (2019). Causes Of Students' Academic Poor Performance Among Graduate Students Of English Department:Students Perspective. IKIP SILIWANGI, 1(11), 83-94.

Rosanti, R. (2017, February 7). Why a motivated teacher is key to the classroom? Accessed from https://www.impactteachers.com/motivated-teacher-key-classroom/teacher-tips.

Sasson, R. (2019, November 18). Lack of motivation and enthusiasm. Accessed from https://www.successconsciousness.com/lack-motivation-enthusiasm.htm.

School, J. (2018, January 20). Low motivation in learners. Accessed from https://japari.co.za/lowmotivation-learners/.

Siqueira, C. M., \& GurGe-Giannetti, J. (2011). Poor school performance: An updated review. Rev Assoc Med Bras, 78-86.

Stover, J. B. (2012). Academic Motivation Scale: adaptation and psychometric analyses for high school and college students. Psychology Research and Behavior Management, 71-83.

Suleman , Q., Aslam, H. D., \& Sarwar, S. (2012). Factors Responsible for Unsatisfactory Academic Performance of the Secondary School Students in the Rural Areas of Kohat Division, Khyber Pukhtunkhwa (Pakistan). American Journal of Scientific Research(43), 46-57.

Whitaker, D. (2012). Neighborhood \& family effects on learning motivation among urban African American middle school youth. HHS Public Access, 131-138.

Williams, E. (2018, June 29). What is the meaning of academic performance? Accessed from https://work.chron.com/meaning-academic-performance-17332.html.

Wong, D. (2017, July 4). 10 common parenting mistakes that demotivate yourchildren.

Accessed from https://www.daniel-wong.com/2017/02/06/demotivate-children/.

Wright, J. (2011). Six reasons why students are unmotivated (and what teachers can do). Intervention Central, 1-26.

Zhenmei. (2014). Factors Interferin Stugdents' Learning Effect in Multimedia-Based ESL Classes in China . The Arts Journal, 21-27. 